\title{
Dietary Arachidonic Acid and Docosahexaenoic Acid Elevate Femur Calcium and Reduce Zinc Content in Piglets
}

\author{
REBECCA C. MOLLARD AND HOPE A. WEILER
}

\begin{abstract}
Department of Human Nutritional Sciences [R.C.M.], University of Manitoba, Winnipeg, Manitoba, R3T 2N2, Canada; School of Dietetics
\end{abstract} and Human Nutrition [H.A.W.], McGill University, Montreal, H9X 3V9, Quebec, Canada

\begin{abstract}
Specific dietary polyunsaturated fatty acids (PUFAs) and long chain PUFAs (LCPUFAs) elevate femur calcium content and enhance calcium balance. Mother's milk is associated with enhanced calcium balance and contains LCPUFAs; arachidonic acid (AA), and docosahexanoic acid (DHA). However, the effect of AA and DHA on calcium metabolism and other bone minerals during infancy is unknown. Thus, piglets received one of four formulas (15 d): control or with AA:DHA (0.5:0.1 g, 1.0:0.2 g, or 2.0:0.4 g/ $100 \mathrm{~g}$ of fat). Calcium absorption, femur mineral composition, and urinary mineral excretion. Main effects identified using two-way analysis of variance (ANOVA) and post hoc analysis conducted using Duncan's multiple range test. Significant effects of diet were observed in femur calcium and zinc content, but not calcium absorption, urinary mineral excretion, femur ash weight, femur phosphorus, or femur magnesium content. The piglets receiving AA:DHA as 1.0:0.2 $\mathrm{g} / 100 \mathrm{~g}$ of fat had $1.9 \%$ higher $\mathrm{mg}$ calcium/g of ash, but $8.6 \%$ lower $\mu \mathrm{g}$ zinc/g of ash compared with control. Thus, AA:DHA in a ratio of 5:1 does not affect mineral accretion, but AA plus DHA, in amounts similar to the upper limit of human milk, might be detrimental to bone mineralization over time due to lower zinc. (Pediatr Res 60: 418-422, 2006)
\end{abstract}

$\mathbf{M}$ other's milk is optimal with respect to calcium absorption by the infant (1). Dietary PUFAs and LCPUFAs affect calcium absorption and balance in animals (2). AA and DHA are present in breast milk (3), but are not considered essential fatty acids. Whether AA and DHA are responsible for enhanced calcium absorption in mother's milk is unknown.

Until recently, formula in North America contained only the essential n-6 and n-3 PUFAs, linoleic acid (LA), and $\alpha$-linolenic acid (ALA). In 2002, the U.S. Food and Drug Administration and Health Canada approved the supplementation of infant formula with AA and DHA. Today, most companies have marketed formula containing AA and DHA, yet the effect of formula with and without AA and DHA on bone mineralization and calcium balance remains unclear. In preterm infants, dietary AA as $0.5 \mathrm{~g} / 100 \mathrm{~g}$ of fat and DHA as $0.3 \mathrm{~g} / 100 \mathrm{~g}$ of fat in formula had no effect on mineral balance (calcium, phosphorus, magnesium, zinc) (4). Also in preterm infants, dietary AA (0.46 g/100 g of fat) and DHA (0.26 g/

Received January 10, 2006; accepted May 22, 2006.

Correspondence: Hope Weiler, Ph.D., School of Dietetics and Human Nutrition, McGill University, Ste. Anne de Bellevue, QC, H9X 3V9, Canada; e-mail: hope.weiler@mcgill.ca

Funded by the Natural Sciences and Engineering Council of Canada.

DOI: $10.1203 / 01$.pdr.0000238255.83621.5e
$100 \mathrm{~g}$ until hospital discharge followed by $0.16 \mathrm{~g} / 100 \mathrm{~g}$ of fat) in formula had no benefits to bone mass through to $1 \mathrm{y}$ corrected age (5). This is in contrast to animal-based research whereby feeding formula with added AA and DHA (0.5:0.1 $\mathrm{g} / 100 \mathrm{~g}$ fat) to piglets increases bone mass by $8 \%$ to $22 \%$ compared with formula with only LA and ALA (6-8). However, higher amounts of AA:DHA (1.0:0.2 and 2.0/0.4 g/100 $\mathrm{g}$ of fat) offered no additional benefit despite keeping the ratio of AA:DHA constant at 5:1 (8).

A proposed mechanism for elevations in bone mass in response to dietary n-6 and n-3 PUFAs and LCPUFAs is altered mineral metabolism (2). Bone contains many minerals, including calcium, phosphorus, magnesium, and zinc, each of which is essential to bone mineralization. Calcium and phosphorus provide structural integrity in the skeleton; $99 \%$ of calcium and $85 \%$ of phosphorus are in the skeleton as hydroxyapatite (9). Approximately $67 \%$ of the body's magnesium is located on the hydroxyapatite surface of bone (9). Magnesium plays a role in calcium metabolism as a cofactor of enzymes required for synthesis of calcitriol (10) and parathyroid hormone (10-13). Thus, magnesium is involved in bone mineral homeostasis and influences hydroxyapatite formation (14). Magnesium affects bone cell function; during deficiency, the number of osteoblasts is decreased and the number of osteoclasts is increased $(15,16)$. Approximately $29 \%$ of zinc is found in bone (17). Zinc is essential in bone metabolism as a cofactor of enzymes (18), including alkaline phosphatase, an important enzyme in bone mineralization (19). Elevations in bone calcium, phosphorus, magnesium, or zinc content could enhance bone mineralization and may explain the higher bone mass seen with dietary LCPUFAs.

The affect of different PUFAs and LCPUFAs on mineral metabolism is unclear. In growing rats, Claassen et al. (2) found that dietary $\gamma$-linolenic acid (GLA) plus eicosapentaenoic acid (EPA) and DHA increased calcium absorption, calcium balance, and bone calcium content. Dietary AA:DHA as 0.5:0.1 $\mathrm{g} / 100 \mathrm{~g}$ of fat had no affect on calcium absorption in piglets following $15 \mathrm{~d}$ (6) or on calcium or phosphorus in tibial diaphysis, plasma, or urine $(6,7)$. It is possible that a

Abbreviations: AA, arachidonic acid; ALA, $\alpha$-linolenic acid; DHA, docosahexaenoic acid; EPA, eicosapentaenoic acid; GLA, $\gamma$-linolenic acid; LA, linoleic acid; LCPUFAs, long-chain polyunsaturated fatty acids; PUFAs, polyunsaturated fatty acids 
higher amount of AA:DHA, as used by Claassen et al. $(7.4 \mathrm{~g} / 100 \mathrm{~g}$ of fat as GLA, $2.5 \mathrm{~g} / 100 \mathrm{~g}$ of fat as EPA and $0.7 \mathrm{~g} / 100 \mathrm{~g}$ as DHA) (2), might enhance mineral balance. Additionally, the effects of dietary LCPUFA on bone magnesium and zinc content in piglets have not been investigated. Thus, the objectives were to determine the effects of varying amounts of AA:DHA (0.5:0.1, 1.0:0.2, 2.0:0.4 g/100 g of fat) in formula versus control formula on 1) calcium absorption, 2) femur mineral composition, and 3) mineral excretion.

\section{METHODS}

Animals and diet. Male piglets $(n=40)$ born at the Glenlea Swine Research Unit, University of Manitoba, were transported to the housing facility at the main campus of the university. The average birth weight $( \pm \mathrm{SD})$ of piglets born at this institution is $1.6 \pm 0.2 \mathrm{~kg}$. Piglets were selected with a birth weight of $\geq 1.4 \mathrm{~kg}$, from 10 litters consisting of 10-12 piglets each with at least four males. Piglets arrived on $\mathrm{d} 3$ of life and were taught to lap liquid formula. Piglets were fed by gavage feeding plus lapping of formula to ensure enough formula was consumed to continue growth for $2 \mathrm{~d}$ of adaptation. The strength of control formula was progressively increased from half strength on $\mathrm{d} 3$ to full strength by the end of $\mathrm{d}$ 4 of life, followed by experimental or control formula on d 5. Piglets were housed individually in stainless steel cages, and room temperature was maintained at $29-30^{\circ} \mathrm{C}$. Based on $0900 \mathrm{~h}$ weight, the piglets were offered $350 \mathrm{~mL} / \mathrm{kg} / \mathrm{d}$ of liquid formula. This amount was chosen based on energy requirements (20) and has been shown to support growth in piglets $(7,21)$. This amount was divided into three equal portions provided at 0900,1500 , and $2100 \mathrm{~h}$ for $15 \mathrm{~d}$ (from 5 to $21 \mathrm{~d}$ of life) per Weiler and Fitzpatrick-Wong (7). Animal care and procedures were examined by the University of Manitoba Committee on Animal Use and were within the guidelines of the Canadian Council of Animal Care (22). This study was a part of a large piglet study that also studied the effects of dietary AA:DHA on bone mass (8).

Piglets were randomized on arrival and within litters to receive one of four dietary treatments. Treatments were control formula or control supplemented with 0.5:0.1 g AA:DHA, 1:0.2 g AA:DHA, or 2:0.4 g AA:DHA per $100 \mathrm{~g}$ of fat. Supplementation was held at a constant $n-6: n-3$ ratio of 5:1. The AA was provided in the form of RBD-ARASCO (40.6 g/100 g of fatty acids as AA) and DHA in the form of RDB-DHASCO ( $40.0 \mathrm{~g} / 100 \mathrm{~g}$ of fatty acids as DHA). AA was derived from a common soil fungi and DHA was derived from a marine microalgae (Martek Biosciences Corp.). These sources were chosen because they were previously used in our laboratory and because they are used in the manufacturing of many infant formula products. Formulas were isocaloric with equal amounts of fat. The formula was based on nutritional requirements for healthy growing piglets between 3 and $10 \mathrm{~kg}$ as set by the National Research Council (21) and currently proven to support growth in our laboratory (7). The dietary composition of the control formula and dietary composition of PUFAs in each treatment formula has been previously published (8). Formula contained $1050 \mathrm{kcal} / \mathrm{L}, 60 \mathrm{~g} / \mathrm{L}$ fat, $50 \mathrm{~g} / \mathrm{L}$ protein, $2.1 \mathrm{~g} / \mathrm{L}$ calcium, $1.4 \mathrm{~g} / \mathrm{L}$ phosphorus, and $6.3 \mathrm{mg} / \mathrm{L}$ zinc. Piglets were allowed approximately $1 \mathrm{~h}$ of exercise before each feed.

Sample collection. Urine was collected over a $24-\mathrm{h}$ period using metabolic cages starting on d 14 and ending on d 15 of study. Urine was collected from $2100 \mathrm{~h}$ to $0900 \mathrm{~h}, 0900 \mathrm{~h}$ to $1500 \mathrm{~h}$, and $1500 \mathrm{~h}$ to $2100 \mathrm{~h}$ and then pooled for analysis. On d 16, the piglets were anesthetized by intraperitoneal injection of sodium pentobarbital ( $30 \mathrm{mg} / \mathrm{kg}, 65 \mathrm{mg} / \mathrm{mL}$ concentration) or isofluorane gas, calcium absorption was measured, and then animals were killed using sodium pentobarbital overdose $(180 \mathrm{mg} / \mathrm{kg})$, and femurs were excised.

Calcium absorption. Calcium absorption was measured using an intestinal ligated loop technique as described previously by Weiler et al. (23). The intestinal ligated loop technique is designed to assess calcium absorption by testing the disappearance of a radiolabeled $\mathrm{Ca}$ isotope across the layers of the intestinal tract. This technique was conducted on the morning of the $d 16$ of the study. Food was removed $12 \mathrm{~h}$ before the procedure. Piglets were anesthetized and a 5- to $10-\mathrm{cm}$ section of duodenum distal to the ligament of Treitz was ligated at both ends using suture, and the duodenal section was then filled with radioisotope buffer solution ( $\mathrm{pH}$ of 7.4, mOsmol of 315) containing ${ }^{45} \mathrm{Ca}(18 \mathrm{MBq} / \mathrm{L}$; Amersham Ltd.), Poly R-478 (100 mg/L; Sigma Chemical Co.-Aldrich Ltd.), mannitol (20 mmol/L; Fisher Scientific), and $\mathrm{CaCl}_{2}(2 \mathrm{mmol} / \mathrm{L}$; Fisher Scientific). Samples were taken every $5 \mathrm{~min}$ for a 30-min period. Samples were analyzed for ${ }^{45} \mathrm{Ca}$ by scintillation counting (Model LS 6000TA; Beckman Instruments Inc.). Poly R-478 was measured by UV spectrometry as described (24). Calcium absorption was calculated according to the method of Ghishan et al. (25).

Bone and urine mineral analysis. Once removed, femurs were cleaned and measurements were taken. Measurements included wet weight $(\mathrm{g})$ and length $(\mathrm{mm})$. Length was measured using calipers to the nearest $0.01 \mathrm{~mm}$. Whole femurs were defatted in acetone (Optima, Fisher Scientific, Allentown, PA) over $5 \mathrm{~d}$ and then ashed in a muffle furnace at $600^{\circ} \mathrm{C}$ for $6 \mathrm{~h}$. The femurs were then ground and weighed to determine ash weight. Femur ash samples $(200 \mathrm{mg})$ were digested in $1.5 \mathrm{~mL}$ concentrated nitric acid and $0.25 \mathrm{~mL}$ of pooled 24-h urine samples were digested in $0.5 \mathrm{~mL}$ concentrated nitric acid for measurement of minerals. Both urine and femur digests were left at room temperature for $48 \mathrm{~h}$ and then diluted to obtain a final concentration of 5\% ( $\mathrm{vol} / \mathrm{vol})$ nitric acid in deionized water. Femur and urinary calcium, phosphorus, magnesium, and zinc determined by inductively coupled plasma optical emission spectroscopy (Varian Liberty 200, Varian Canada, Mississauga, ON, Canada). The coefficient of variance for each mineral was $<10 \%$. Minerals were expressed per gram of bone before ashing representing bone mineral relative to bone matrix and also per gram of bone ash to reflect the relative proportions of each mineral within bone.

Statistical analysis. Main effects were detected using two-way ANOVA (diet and litter) using SAS statistical software (SAS software release 8.2; SAS Institute, Cary, NC). Litter was included in the statistical analysis as a main effect because previous research demonstrated that litter has a strong effect on bone parameters (21). Post hoc analysis was conducted using Duncan's Multiple Range Test when main effects were detected by the two-way ANOVA. Body weight was explored as a covariate in the analysis, but yielded the same interpretation as the two-way ANOVA; results of the unadjusted two-way ANOVA are presented for clarity of presentation. A P-value of less than 0.05 was accepted as significant. Data are expressed as mean \pm SEM (SEM).

\section{RESULTS}

At the start of the study, there were no differences among the groups in weight (range $2.00-2.14 \mathrm{~kg}$ ). By the end of the feeding trial, weight remained consistent among the groups and ranged on average from 5.48 to $5.63 \mathrm{~kg}$ among the dietary groups. Accordingly, there were also no differences among groups in length, ranging from 53.7 to $54.2 \mathrm{~cm}$, at the end of the study. There were no differences among groups in feed intake because the piglets consumed all the formula they were given at each feed $(350 \mathrm{~mL} / \mathrm{kg} / \mathrm{d})$.

There were no dietary effects on calcium absorption corrected to intestinal weight (control $10.5 \pm 1.1 ; 0.5: 0.1 \mathrm{~g}$, AA:DHA $9.0 \pm 0.5 ; 1.0: 0.2 \mathrm{~g}$, AA:DHA $9.4 \pm 1.1 ; 2.0: 0.4 \mathrm{~g}$, AA:DHA $9.2 \pm 0.7 \mathrm{mmol} / 30 \mathrm{~min} / \mathrm{g}$ intestine). The average calcium absorption for all animals was $84 \%$. No dietary effects were observed on femur wet weight, length, or ash weight (Table 1). There was a significant main effect of diet on femur calcium when expressed as $\mathrm{mg} / \mathrm{g}$ of femur ash $(p=0.0498)$ (Table 2). The 1.0:0.2 g AA:DHA group had significantly

Table 1. Femur wet weight, length, and ash weight of piglets fed formula with AA:DHA for $15 d$ versus control*

\begin{tabular}{lcccc}
\hline & & \multicolumn{3}{c}{ AA:DHA diets $(\mathrm{g} / 100 \mathrm{~g}$ of fat) } \\
\cline { 3 - 4 } & Control diet & $0.5: 0.1$ & $1.0: 0.2$ & $2.0: 0.4$ \\
\hline Wet weight $(\mathrm{g})$ & $23.00 \pm 5.93$ & $23.67 \pm 6.31$ & $22.58 \pm 6.80$ & $22.66 \pm 4.92$ \\
Length $(\mathrm{mm})$ & $77.9 \pm 0.8$ & $79.0 \pm 0.8$ & $78.1 \pm 0.8$ & $77.8 \pm 0.8$ \\
Ash weight $(\mathrm{g})$ & $3.45 \pm 0.26$ & $3.54 \pm 0.26$ & $3.37 \pm 0.25$ & $3.28 \pm 0.19$ \\
\hline
\end{tabular}

* Data expressed as mean $\pm \mathrm{SEM}, n=32$ 
Table 2. Femur mineral content of piglets fed formula with AA:DHA for 15 d versus control*

\begin{tabular}{|c|c|c|c|c|c|}
\hline & Control diet & \multicolumn{4}{|c|}{ AA:DHA diets $(\mathrm{g} / 100 \mathrm{~g}$ of fat $)$} \\
\hline \multicolumn{6}{|l|}{$\mathrm{Ca}$} \\
\hline $\mathrm{mg} / \mathrm{femur}$ & $1974.07 \pm 146.14$ & $2051.85 \pm 142.23$ & $1968.76 \pm 139.41$ & $1881.62 \pm 111.05$ & 0.6745 \\
\hline \multicolumn{6}{|l|}{$\mathrm{Zn}$} \\
\hline$\mu \mathrm{g} / \mathrm{g}$ of ash & $215.46 \pm 2.93^{\mathrm{b}}$ & $210.36 \pm 6.38^{\mathrm{ab}}$ & $196.91 \pm 6.89^{\mathrm{a}}$ & $202.30 \pm 5.14^{\mathrm{ab}}$ & 0.0227 \\
\hline $\mathrm{mg} / \mathrm{g}$ of ash & $357.87 \pm 1.33$ & $359.67 \pm 2.27$ & $364.37 \pm 3.60$ & $358.61 \pm 1.02$ & 0.2236 \\
\hline $\mathrm{mg} / \mathrm{femur}$ & $1231.67 \pm 91.30$ & $1305.72 \pm 88.14$ & $1221.29 \pm 93.18$ & $1174.33 \pm 76.18$ & 0.7673 \\
\hline \multicolumn{6}{|l|}{$\mathrm{Mg}$} \\
\hline $\mathrm{mg} / \mathrm{g}$ of ash & $6.21 \pm 0.12$ & $6.12 \pm 0.10$ & $6.12 \pm 0.15$ & $6.22 \pm 0.12$ & 0.8860 \\
\hline $\mathrm{mg} / \mathrm{femur}$ & $21.35 \pm 1.57$ & $21.78 \pm 1.82$ & $20.55 \pm 1.35$ & $20.46 \pm 1.40$ & 0.7539 \\
\hline
\end{tabular}

* Data expressed as mean $\pm \mathrm{SEM}, n=32$. Different subscripts identify differences among dietary treatment groups where a $<\mathrm{b}<\mathrm{c}$.

$\mathrm{Mg}$, magnesium; P, phosphorus; Zn, zinc.

higher femur calcium than control and the 2.0:0.4 g AA:DHA group, while the 0.5:0.1 g AA:DHA had intermediate values. There were no diet effects on femur calcium when expressed per whole femur (g) (Table 2) or per length (control $25.3 \pm$ 1.7; 0.5:0.1 g, AA:DHA $25.8 \pm 1.1 ; 1.0: 0.2$ g, AA:DHA $25.1 \pm 1.3 ; 2.0: 0.4 \mathrm{~g}$, AA:DHA $24.1 \pm 1.0$ ). There was a significant main effect of diet on femur zinc when expressed as $\mu \mathrm{g} / \mathrm{g}$ of femur ash $(p=0.0227)$ (Table 2). The 1.0:0.2 g AA:DHA group had significantly lower values compared with control, while the 0.5:0.1 g AA:DHA and 2.0:0.4 g AA:DHA groups had intermediate values. There was no effect of diet on femur zinc when expressed per whole femur $(\mu \mathrm{g} / \mathrm{g}$ ) (Table 2) or per femur length (control 9.5 $\pm 0.8 ; 0.5: 0.1 \mathrm{~g}$, AA:DHA $9.3 \pm 0.5 ; 1.0: 0.2 \mathrm{~g}, \mathrm{AA}:$ DHA $8.5 \pm 0.5 ; 2.0: 0.4 \mathrm{~g}$, AA:DHA $8.5 \pm 0.4 \mu \mathrm{g} / \mathrm{mm})$. There were no main effects of diet on femur phosphorus expressed per g, whole femur (Table 2) or per femur length (control 15.8 \pm 1.1; 0.5:0.1 g AA:DHA 16.0 $\pm 0.7 ; 1.0: 0.2$ g AA:DHA $15.6 \pm 0.8 ; 2.0: 0.4$ g AA:DHA $15.1 \pm 0.6 \mathrm{mg} / \mathrm{mm})$. There were no main effects of diet on femur magnesium expressed per g, whole femur (Table 2) or per femur length (control $273 \pm 18 ; 0.5: 0.1 \mathrm{~g}$, AA:DHA $273 \pm 18 ; 1.0: 0.2$ g, AA:DHA $262 \pm 12 ; 2.0: 0.4$ g, AA:DHA $262 \pm 13 \mathrm{mg} / \mathrm{mm})$.
Diet did not affect urinary calcium, phosphorus, magnesium, or zinc when expressed as over a $24-\mathrm{h}$ period (mmol) or when corrected to the weight of the animal ( $\mathrm{mmol} / \mathrm{kg}$ ) (Table 3).

\section{DISCUSSION}

This is the first study to report the effects of dietary AA and DHA on the composition of bone mineral including calcium, phosphorus, magnesium, and zinc during infancy. Dietary AA:DHA did not alter femur growth or mineral content when added in amounts $(0.5: 0.1 \mathrm{~g} / 100 \mathrm{~g}$ of fat) similar to that observed in human milk of Canadians (26). Higher amounts of AA:DHA at 1.0:0.2 g/100 g of fat, but not 2.0:0.4 g/100 g of fat elevated calcium and reduced zinc, but had no effect on magnesium or phosphorus in the femur. In agreement with previous piglet studies on calcium and phosphorus content in tibial diaphysis sections, without periosteum $(6,7)$, whole femur calcium and phosphorus contents were unchanged with dietary AA:DHA as 0.5:0.1 g/100 g of fat. The alterations in femur calcium and zinc in the piglets fed 1.0:0.2 g/100 g of fat as AA:DHA may be related to reduced bone resorption (8) and possibly higher proportions of less mature woven bone that are known to mineralize more quickly (27). Regardless, di-

Table 3. Urinary mineral excretion of piglets fed formula supplemented with AA:DHA for $15 d$ versus control*

\begin{tabular}{|c|c|c|c|c|c|}
\hline & Control diet & \multicolumn{3}{|c|}{ AA:DHA diets ( $\mathrm{g} / 100 \mathrm{~g}$ of fat) } & $p$ value \\
\hline \multicolumn{6}{|l|}{$\mathrm{Ca}$} \\
\hline $\mathrm{mmol} / 24 \mathrm{~h} / \mathrm{kg}$ & $166.6 \pm 27.2$ & $162.1 \pm 50.2$ & $270.3 \pm 89.9$ & $144.4 \pm 37.7$ & 0.2187 \\
\hline \multicolumn{6}{|l|}{$\mathrm{P}$} \\
\hline $\mathrm{mmol} / 24 \mathrm{~h}$ & $625.8 \pm 40.1$ & $483.5 \pm 157.1$ & $569.6 \pm 330.7$ & $564.2 \pm 181.6$ & 0.9416 \\
\hline $\mathrm{mmol} / 24 \mathrm{~h}$ & $1322.7 \pm 211.0$ & $1244.1 \pm 190.2$ & $1206.6 \pm 275.6$ & $1258.5 \pm 230.3$ & 0.9998 \\
\hline $\mathrm{mmol} / 24 \mathrm{~h} / \mathrm{kg}$ & $242.4 \pm 39.2$ & $219.6 \pm 29.1$ & $205.8 \pm 43.7$ & $225.2 \pm 41.4$ & 0.9924 \\
\hline \multicolumn{6}{|l|}{$\mathrm{Zn}$} \\
\hline$\mu \mathrm{mol} / 24 \mathrm{~h}$ & $16.1 \pm 6.3$ & $18.4 \pm 6.2$ & $11.3 \pm 1.6$ & $225.2 \pm 41.4$ & 0.5974 \\
\hline$\mu \mathrm{mol} / 24 \mathrm{~h} / \mathrm{kg}$ & $3.1 \pm 1.4$ & $3.3 \pm 1.1$ & $2.0 \pm 0.2$ & $2.1 \pm 0.5$ & 0.4937 \\
\hline
\end{tabular}

* Data expressed as mean $\pm \mathrm{SEM}, n=32$. 
etary AA:DHA did not increase femur total ash weight or total calcium, in line with no change to bone mineral content or bone mineral density, as previously reported (8).

The effects of dietary PUFAs and LCPUFAs on femur mineral content and growth have been studied in rats. In growing rats, dietary GLA plus EPA/DHA in a total n-6:n-3 ratio of 3:1 (GLA $7.4 \mathrm{~g} / 100 \mathrm{~g}$ of fat and EPA/DHA $2.5 \mathrm{~g} /$ $100 \mathrm{~g}$ of fat) and 1:1 (GLA $6.6 \mathrm{~g} / 100$ of fat and EPA/DHA $5.0 \mathrm{~g} / 100 \mathrm{~g}$ of fat) resulted in higher amounts of calcium in bone compared with control, but a ratio of 1:3 (GLA $5.2 \mathrm{~g} / 100$ $\mathrm{g}$ of fat and EPA/DHA $12.4 \mathrm{~g} / 100 \mathrm{~g}$ of fat) had no effect (2). GLA and EPA/DHA did not alter femoral ash weight or length (2). Other studies in which only n-3 LCPUFAs were supplemented through use of fish oil $(28,29)$ did not yield any change to femur weight, length, ash weight, calcium, magnesium, or phosphorus in growing rats (28). Thus, it appears that both $\mathrm{n}-6$ and n-3 LCPUFAs are required to elevate femur calcium content. The rats used by Claassen et al. (2) ate 20-22 g food/d and had a final weight of $350 \mathrm{~g}$. Given the proportion of LCPUFAs in the diets, the rats consumed $0.3 \mathrm{~g}$ GLA $/ \mathrm{kg}$, $0.07 \mathrm{~g} \mathrm{EPA} / \mathrm{kg}$, and $0.02 \mathrm{~g} \mathrm{DHA} / \mathrm{kg}$ of body weight in the $3: 1$ n-6/n-3 group. In our piglet study, the amounts of LCPUFAs for the group receiving 1.0:0.2 $\mathrm{g} / 100 \mathrm{~g}$ of fat as AA:DHA were $0.22 \mathrm{~g} \mathrm{AA} / \mathrm{kg}$ and $0.04 \mathrm{~g}$ DHA $/ \mathrm{kg}$ of body weight. These studies suggest that dietary n-6 (GLA or AA) and n-3 (EPA and/or DHA) PUFAs that bypass the rate-limiting step of $\Delta-6$ desaturase are needed in a ratio from 3:1 to $5: 1$ to observe elevations in bone calcium. None of these studies investigated the effects of dietary n-6 and n-3 PUFAs and LCPUFAs on bone zinc content.

Dietary AA:DHA at 1.0:0.2 g/100 $\mathrm{g}$ of fat reduced femur zinc. During zinc deficiency, the amount of zinc in the bone decreases because bone is an endogenous source of zinc when the dietary supply is low (30). Dietary zinc intake was not different among the groups of piglets, which suggests that zinc metabolism is altered in response to LCPUFA. Retention of zinc was not affected by diet as indicated by urinary zinc values. A possible explanation for lower femur zinc is that intestinal absorption is reduced or bone uptake is reduced because it is being accumulated or used in other tissues. In rats, bone zinc content stabilizes after weanling (31) and with reductions in the zinc content of bone ash, there are significant reductions in bone mineral mass (32). In a normal adult, approximately $29 \%$ of body zinc is found in bone (17) and those who suffer from bone fracture have lower bone zinc content (33). Thus, the longer term implications of lower bone zinc herein require investigation.

An important objective of this study was to confirm that dietary AA:DHA does not alter calcium absorption during rapid growth (6). Dietary AA:DHA at 0.5:0.1 g/100 g of fat, and up to 4-fold higher amounts, in formula containing a total n-6:n-3 ratio of 5:1 does not alter calcium absorption. In growing rats, dietary GLA and EPA plus DHA with a total n-6:n-3 ratio of 3:1 and 1:1 increased calcium absorption by $45 \%$ and $21.4 \%$, respectively using mass balance, compared with control rats fed LA and ALA (total n-6:n-3 ratio of 3:1) (2). The lack of increase in calcium absorption in piglets may be the result of already optimal calcium transport (84\% ab- sorption) compared with the older growing rats; the different animal models (rat versus piglet); and the in situ ligated loop did not represent whole intestinal absorption. In piglets, calcium absorption was measured at $84 \%$, whereas in rats, although the percentage of calcium absorbed was not stated, calcium absorption was increased by up to $45 \%$ (2). It is most likely that the differences between these two studies were due to the animal's developmental ages rather than the specific amounts of PUFAs because in human preterm infants dietary AA:DHA also did not affect mineral balance (4).

The final objective of this study was to determine whether dietary AA:DHA alters urinary mineral excretion; no effects of AA:DHA were observed. In growing rats, dietary GLA plus EPA/DHA supplemented to achieve a total n-6:n-3 ratio of 1:3 (GLA $5.2 \mathrm{~g} / 100 \mathrm{~g}$ of fat and EPA/DHA $12.4 \mathrm{~g} / 100 \mathrm{~g}$ of fat) reduced urinary calcium excretion, whereas a total n-6:n-3 ratio of 3:1 increased urinary calcium (2), suggesting that the dietary n-6:n-3 ratio is related to calcium excretion rather than specific amounts of PUFAs. The current study supports this thesis because the total n-6:n-3 PUFA ratio was constant. However, diets made with menhaden oil versus those made with soybean oil had no effect on urinary calcium in healthy $(28,29)$ or diabetic $(29)$ rats. A menhaden oil diet has a much lower total n-6:n-3 ratio compared with a soybean oil diet. AA status resulting from a high consumption of n-6 PUFA increases calcium excretion (34). Whether it is the total n-6:n-3 ratio or the amount of specific PUFAs/LCPUFAs that influence calcium excretion requires further investigation.

In conclusion, higher whole body or lumbar spine BMD found in piglets supplemented with $0.5: 0.1 \mathrm{~g} / 100 \mathrm{~g}$ of fat as AA:DHA was not explained by alterations in calcium absorption, bone mineral composition or mineral excretion. The specific minerals in the whole body and lumbar spine were not measured, therefore, alterations in mineral composition therein cannot be ruled out. Dietary AA:DHA as 1.0:0.2 g/100 $\mathrm{g}$ of fat increased femur calcium (per $\mathrm{g}$ of femoral ash) and reduced bone resorption (8). A longer term study may have shown improved bone mass through reduced bone resorption and higher bone calcium. In addition, mineral balance was not measured in this study and could potentially explain why dietary AA:DHA at 1.0:0.2 g/100 g of fat resulted in altered bone calcium and zinc content. Research is needed to determine the mechanism for increased femoral calcium and reduced femoral zinc content. Whether the decrease in femur zinc seen here is detrimental to bone is unknown and requires further investigation.

Acknowledgments. The authors thank Heather Kovacs, Shirley Fitzpatrick-Wong, Jinping Zhao, Melani Olthius, Sarah Kolley, Jennifer Zahradka, and staff of the Animal Holding Facility for animal care.

\section{REFERENCES}

1. Institute of Medicine 1997 Dietary Reference Intakes for Calcium, Phosphorus, Magnesium, Vitamin D, and Fluoride. National Academy Press, Washington, DC

2. Claassen N, Coetzer H, Steinmann CM, Kruger MC 1995 The effect of different n-6/n-3 essential fatty acid ratios on calcium balance and bone in rats. Prostaglandins Leukot Essent Fatty Acids 53:13-19 
3. Hoffman DR, Birch EE, Castaneda YS, Fawcett SL, Wheaton DH, Birch DG, Uauy R 2003 Visual function in breast-fed term infants weaned to formula with or without long-chain polyunsaturates at 4 to 6 months: a randomized clinical trial. J Pediatr 142:669-677

4. Martinez FE, Sieber VM, Jorge SM, Ferlin ML, Mussi-Pinhata MM 2002 Effect of supplementation of preterm formula with long chain polyunsaturated fatty acids on mineral balance in preterm infants. J Pediatr Gastroenterol Nutr 35:503-507

5. Groh-Wargo S, Jacobs J, Auestad N, O'Connor DL, Moore JJ, Lerner E 2005 Body composition in preterm infants who are fed long-chain polyunsaturated fatty acids: a prospective, randomized, controlled trial. Pediatr Res 57:712-718

6. Weiler HA 2000 Dietary supplementation of arachidonic acid is associated with higher whole body weight and bone mineral density in growing pigs. Pediatr Res 47:692-697

7. Weiler HA, Fitzpatrick-Wong S 2002 Dietary long-chain polyunsaturated fatty acids minimize dexamethasone- induced reductions in arachidonic acid status but not bone mineral content in piglets. Pediatr Res 51:282-289

8. Mollard RC, Kovacs HR, Fitzpatrick-Wong SC, Weiler HA 2005 Low levels of dietary arachidonic and docosahexaenoic acids improve bone mass in neonatal piglets, but higher levels provide no benefit. J Nutr 135:505-512

9. Broadus AE 1999 Mineral balance and homeostasis. In: Flavus MJ (ed) Primer on the Metabolic Diseases and Disorders of Mineral Metabolism. Lippincott Williams \& Wilkins, Philadelphia, pp 74-79

10. Connor TB, Toskes P, Mahaffey J, Martin LG, Williams JB, Walser M 1972 Parathyroid function during chronic magnesium deficiency. John Hopkins Med J 131:100-117

11. Rude RK, Oldham SB, Singer FR 1976 Functional hypoparathyroidism and parathyroid hormone end-organ resistance in human magnesium deficiency. Clin Endocrinol (Oxf) 5:209-224

12. Rude RK, Oldham SB, Sharp CF Jr, Singer FR 1978 Parathyroid secretion in magnesium deficiency. J Clin Endocrinol Metab 47:800-806

13. Rude RK, Adams JS, Ryzen E, Endres DB, Niimi H, Horst RL, Haddad JG Jr, Singer FR 1985 Low serum concentrations of 1,25-dihydroxyvitamin D in human magnesium deficiency. J Clin Endocrinol Metab 61:933-940

14. Wallach S 1990 Effects of magnesium on skeletal metabolism. Magnes Trace Elem 9:1-14

15. Rude RK, Gruber HE, Wei LY, Frausto A, Mills BG 2003 Magnesium deficiency: effect on bone and mineral metabolism in the mouse. Calcif Tissue Int 72:32-41

16. Rude RK, Kirchen ME, Gruber HE, Meyer MH, Luck JS, Crawford DL 1999 Magnesium deficiency-induced osteoporosis in the rat: uncoupling of bone formation and bone resorption. Magnes Res 12:257-267

17. Jackson MA, Slininger PJ, Bothast RJ 1989 Effects of zinc, iron, cobalt, and manganese on Fusarium moniliforme NRRL 13616 growth and fusarin C biosynthesis in submerged cultures. Appl Environ Microbiol 55:649-655

18. Saltman PD, Strause LG 1993 The role of trace minerals in osteoporosis. J Am Coll Nutr 12:384-389
19. Yamaguchi M, Yamaguchi R 1986 Action of zinc and bone metabolism in rats. Increases in alkaline phosphatase activity and DNA content. Biochem Pharmacol 35:773-777

20. National Research Council 1996 Institute of Laboratory Animal Resources, Commission on Life Sciences. Guide for the Care and Use of Laboratory Animals. National Academy Press, Washington, DC

21. Blanaru JL, Kohut JR, Fitzpatrick-Wong SC, Weiler HA 2004 Dose response of bone mass to dietary arachidonic acid in piglets fed cow milk-based formula. Am J Clin Nutr 79:139-147

22. Canadian Council on Animal Care 1993 Guide to the care and use of experimental animals, 2nd ed. Bradda Printing Services Inc., Ottawa, Canada

23. Weiler HA, Wang Z, Atkinson SA 1995 Dexamethasone treatment impairs calcium regulation and reduces bone mineralization in infant pigs. Am J Clin Nutr 61:805-811

24. Stahl GE, Fayer JC, Ling SC, Watkins JB 1991 Comparison of nonabsorbable markers Poly R-478 and $\left[{ }^{14} \mathrm{C}\right]$ PEG-4000 for use in developmental absorption studies. J Pediatr Gastroenterol Nutr 110:485-493

25. Ghishan FK, Jenkins JT, Younoszai MK 1980 Maturation of calcium transport in the rat small and large intestine. J Nutr 110:1622-1628

26. Hibbeln JR 2002 Seafood consumption, the DHA content of mothers' milk and prevalence rates of postpartum depression: a cross-national, ecological analysis. J Affect Disord 69:15-29

27. Gorski JP 1998 Is all bone the same? Distinctive distributions and properties of non-collagenous matrix proteins in lamellar vs. woven bone imply the existence of different underlying osteogenic mechanisms. Crit Rev Oral Biol Med 9:201-223

28. Kelly O, Cusack S, Jewell C, Cashman KD 2003 The effect of polyunsaturated fatty acids, including conjugated linoleic acid, on calcium absorption and bone metabolism and composition in young growing rats. Br J Nutr 90:743-750

29. Green KH, Wong SC, Weiler HA 2004 The effect of dietary n-3 long-chain polyunsaturated fatty acids on femur mineral density and biomarkers of bone metabolism in healthy, diabetic and dietary-restricted growing rats. Prostaglandins Leukot Essent Fatty Acids 71:121-130

30. Jackson MJ, Jones DA, Edwards RH 1982 Tissue zinc levels as an index of body zinc status. Clin Physiol 2:333-343

31. Yamaguchi M, Ozaki K, Suketa Y 1989 Alteration in bone metabolism with increasing age: effects of zinc and vitamin D3 in aged rats. J Pharmacobiodyn 12:67-73

32. Matzsch T, Bergqvist D, Hedner U, Nilsson B, Ostergaard P 1990 Effects of low molecular weight heparin and unfragmented heparin on induction of osteoporosis in rats. Thromb Haemost 63:505-509

33. Helliwell TR, Kelly SA, Walsh HP, Klenerman L, Haines J, Clark R, Roberts NB 1996 Elemental analysis of femoral bone from patients with fractured neck of femur or osteoarthrosis. Bone 18:151-157

34. Baggio B, Budakovic A, Priante G, Gambaro G, Manzato E, Khan S 2002 Dietary fatty acid supplementation modulates the urinary excretion of calcium and oxalate in the rat. Insight into calcium lithogenesis. Nephron 91:486-491 